doi:10.12662/2359-618xregea.v8i2.p46-60.2019

\title{
ARTIGOS
}

\section{NÍVEL DE DIVULGAÇÃO DO PASSIVO CONTINGENTE: UM ESTUDO NOS BANCOS LISTADOS NA BM\&FBOVESPA}

\section{LEVEL OF DISCLOSURE OF CONTINGENT LIA- BILITIES: A STUDY OF BANKS LISTED ON BM \& FBOVESPA}

\section{RESUMO}

O presente estudo objetiva avaliar o nível de divulgação do passivo contingente dos bancos listados nos segmentos diferenciados de governança corporativa da BM\&FBovespa nos demonstrativos financeiros de 2014 a 2016. Este estudo consiste em uma pesquisa qualitativa, classificada como descritiva. O procedimento metodológico adotado para a coleta de dados foi a análise documental. A amostra foi composta por dez companhias, e os resultados apontam que a média do nível de divulgação foi de $63 \%$. Constatou-se que, das dez empresas analisadas, seis apresentaram o nível acima da média e quatro ficaram abaixo. Para este artigo, priorizou-se a descrição de seis empresas, três com nível acima da média e três com nível abaixo. Observou-se que os passivos contingentes mais encontrados foram tributários, trabalhistas e cíveis, respectivamente. Percebeu-se que as companhias ainda não estão cumprindo adequadamente as exigências estabelecidas pelo CPC 25 (2009); porém, a maioria apresentou níveis de divulgação satisfatórios.

Palavras-chave: Passivos Contingentes. Divulgação. CPC 25. Governança Corporativa.

Camila Silva Nascimento d.camylla@hotmail.com Graduada em Ciências Contábeis pelo Centro Universitário Christus (Unichristus). Fortaleza - CE - BR.

Jorge Alberto de Saboia Arruda jorge.saboia@sefaz.ce.gov.br Mestre em Economia. Graduado em Administração. Professor do Centro Universitário Christus (Unichristus). Fortaleza - CE - BR.

\begin{abstract}
The present study aims to evaluate the level of disclosure of the contingent liabilities of listed banks in the differentiated segments of corporate governance of BM\&FBovespa in the financial statements from 2014 to 2016. A qualitative research, classified as descriptive. The methodological procedure adopted for the data collection was documental analysis. The sample consisted of ten companies and the results indicate that the average level of disclosure was $63 \%$. It was verified that of the 10 companies analyzed, six were above average and four were below. For this article, we prioritized the description of 6 companies, 3 with above average
\end{abstract}


level and 3 with level below. It was observed that the most frequent contingent liabilities were tax, labor and civil, respectively. It was noticed that the companies are not yet adequately complying with the requirements established by CPC 25 (2009), however, the majority presented satisfactory levels of disclosure.

Keywords: Contingent Liabilities. Disclosure. CPC 25. Corporate Governance.

\section{INTRODUÇÃO}

No Brasil, a adequação às normas internacionais de contabilidade veio com as Leis 11.638/2007 e 11.941/2009, que determinaram a adoção dos pronunciamentos técnicos emitidos pelo Comitê de Pronunciamentos Contábeis (CPC). Essas normas têm o objetivo de direcionar o modo como as empresas divulgam as demonstrações financeiras, proporcionando maior comparabilidade e qualidade nas informações prestadas e, assim, tornando o processo de tomada de decisão mais eficiente (CASTRO JUNIOR, 2013; SUAVE et al., 2013).

O pronunciamento técnico CPC 25 trata, entre outros aspectos, dos critérios de reconhecimento e base de mensuração apropriada às provisões, ao passivo e ativo contingente e da divulgação em notas explicativas de informações relacionadas à sua natureza, oportunidade e valor (COMITÊ DE PRONUNCIAMENTOS CONTÁBEIS, 2009). Quanto às companhias abertas, a Deliberação n ${ }^{0}$ 594/2009 da Comissão de Valores Mobiliários (CVM) tornou obrigatória a aplicação do Pronunciamento Técnico CPC 25, a partir de 2010. Enquanto em relação às instituições financeiras, o Banco Central do Brasil (BACEN) emitiu a Resolução $n^{0}$ 3.823/2009 que determina a observância do CPC 25 a partir de 2010 .

Diante da publicação dessas normas e da preocupação dos usuários da contabilidade com a qualidade das informações contábeis, o passivo ganhou destaque devido à necessidade de demonstrar a real situação líquida da entidade e da avaliação dos riscos inerentes à atividade da entidade (CAETANO et al., 2010; SUAVE et al., 2013). Assim, este artigo tem como objetivo avaliar o nível de divulgação do passivo contingente dos bancos listados nos segmentos diferenciados de governança corporativa da BM\&FBovespa nos demonstrativos financeiros de 2014 a 2016.

Os segmentos diferenciados de governança corporativa (Novo Mercado, Nível 1 e Nível 2) são direcionados às companhias que se comprometem com a adoção de práticas de governança corporativa adicionais às exigidas em lei (BM\&FBOVESPA, 2016). Fonteles et al. (2013) constataram que as empresas listadas no Novo Mercado e nos Níveis 1 e 2 de Governança Corporativa apresentam nível de disclosure mais elevado quando comparado com as demais empresas. Castro Junior (2013) afirma que as empresas listadas nesses segmentos possuem critérios mais rígidos de evidenciação. Dessa maneira, optou-se, nesta pesquisa, por restringir a análise às instituições financeiras listadas nos segmentos diferenciados de governança corporativa.

\section{REVISÃO DE LITERATURA}

\subsection{PASSIVO}

O passivo refere-se a compromissos assumidos com terceiros, que devem ter seus valores reconhecidos e destacados no Balanço Patrimonial da entidade. O Pronunciamento Conceitual Básico CPC 00 R1, emitido em 2011 pelo CPC para fundamentar a elaboração e a divulgação das demonstrações contábeis, no item 4.4 b, define o passivo como "uma obriga- 
ção presente da entidade, derivada de eventos passados, cuja liquidação se espera que resulte na saída de recursos da entidade capazes de gerar benefícios econômicos." (COMITÊ DE PRONUNCIAMENTOS CONTÁBEIS, 2011, p. 23). A definição apresenta três características essenciais: uma obrigação presente da entidade, resultado de transações ou eventos passados, e a liquidação implicará a saída de recursos geradores de benefícios futuros (COMITÊ DE PRONUNCIAMENTOS CONTÁBEIS, 2011; NIYAMA; SILVA, 2013).

As obrigações são criadas a partir de um evento, que faz que a entidade não tenha nenhuma alternativa realista senão liquidar a obrigação. A não liquidação pode gerar penalidades significativas para a entidade (COMITÊ DE PRONUNCIAMENTOS CONTÁBEIS, 2009; NIYAMA; SILVA, 2013). Uma obrigação pode ser legal ou não formalizada. Obrigação legal é oriunda de um contrato, de uma legislação ou de outra ação da lei. A não formalizada decorre de ações da entidade que indicam a outras partes que aceitará certas responsabilidades e cria expectativas válidas de que cumprirá com essas responsabilidades (COMITÊ DE PRONUNCIAMENTOS CONTÁBEIS, 2009). Para ser considerado um passivo, a obrigação deve ser resultado de um evento passado (FARIAS, 2004).

A existência de um passivo indica que, futuramente, a entidade deverá utilizar recursos incorporados de benefícios econômicos para sua liquidação. De acordo com o CPC 00 R1 (COMITE DE PRONUNCIAMENTOS CONTÁBEIS, 2011), isso pode ocorrer de diversas formas, como, por meio de pagamento em caixa, transferência de ativos, prestação de serviços, substituição de uma obrigação por outra, conversão da obrigação em item do patrimônio líquido, renúncia por parte do credor ou pela perda de seus direitos.

O CPC 00 R1 (COMITÊ DE PRONUNCIAMENTOS CONTÁBEIS, 2011) destaca que os elementos patrimoniais serão reconhecidos na demonstração contábil se: (a) for provável que algum benefício econômico futuro associado ao item flua para a entidade ou flua da entidade; e (b) o item tiver custo ou valor que possa ser mensurado com confiabilidade.

A primeira condição para o reconhecimento é que o elemento atenda a definição de passivo. A segunda é que ele possua valor que possa ser mensurado com confiabilidade ou possa ser estimado com razoabilidade, pois o uso de estimativas razoáveis não altera sua confiabilidade. A falta de reconhecimento não é corrigida pela divulgação de notas explicativas e outros materiais explicativos nem das práticas contábeis adotadas (COMITE DE PRONUNCIAMENTOS CONTÁBEIS, 2011; NIYAMA; SILVA, 2013).

Quanto à classificação, os passivos podem ser classificados quanto à sua ocorrência (normais ou contingentes), quanto à sua liquidação (monetários ou não monetários) e quanto à sua evolução (onerosos ou não onerosos) (FARIAS, 2004). Dessa maneira, serão apresentados a seguir os passivos contingentes e as provisões.

\subsection{PROVISÕES E PASSIVOS CON- TINGENTES}

Deve-se ressaltar que, inicialmente, o CPC 25 (COMITÊ DE PRONUNCIAMENTOS CONTÁBEIS, 2009) define provisão como um passivo de prazo ou de valor incertos. Logo, as provisões são diferenciadas dos passivos quando há incerteza sobre os prazos ou os valores que serão desembolsados ou exigidos para sua liquidação. Dessa forma, uma provisão deve ser reconhecida quando atender ao conceito de passivo e puder ser feita uma estimativa confiável do montante da obrigação. $\mathrm{O}$ valor reconhecido como provisão deve ser a melhor estimativa, valor requerido na hipótese de a entidade pagar ou transferir a obrigação para terceiros na data do balanço (COMITÊ DE PRONUNCIAMENTOS CONTÁBEIS, 2009; GELBCKE et al., 2013).

O passivo contingente é um tipo de passivo que, para sua efetivação, depende da ocorrência ou não de um evento no futuro. Esse evento pode resultar em ganhos ou perdas para a entidade e não está totalmente sob o controle (COMITÊ DE PRONUNCIAMENTOS CONTÁBEIS, 
2009; CAETANO et al., 2010). É, também, uma obrigação presente derivada de eventos passados que não é reconhecida porque não é provável a saída de recursos para sua liquidação, ou seu valor não pode ser estimado com confiabilidade suficiente. Adicionalmente, o termo passivo contingente é usado para passivos que não satisfaçam os critérios de reconhecimento (COMITÊ DE PRONUNCIAMENTOS CONTÁBEIS, 2009; GARCIA, 2015). A partir do quadro 1, é possível observar a definição e o tratamento contábil direcionado a cada classificação.

\subsection{TEORIA DA DIVULGAÇÃO}

A evidenciação ou disclosure contábil trata de uma das etapas do processo contábil; diz respeito à apresentação ordenada das transações e aos eventos ocorridos no patrimônio das organizações, propiciando uma base de informações adequada (CASTRO JUNIOR, 2013). Neste estudo, os termos evidenciação, disclosure e divulgação serão tratados como sinônimos, e signifi-

Quadro 1 - Tipos de passivo contingente e tratamento contábil

\begin{tabular}{|c|l|l|}
\hline Possibilidade & \multicolumn{1}{|c|}{ Definição } & \multicolumn{1}{c|}{ Tratamento Contábil } \\
\hline Provável & $\begin{array}{l}\text { Provavelmente, requer uma saída de } \\
\text { recursos. }\end{array}$ & $\begin{array}{l}\text { Será reconhecida a provisão e divulgada em } \\
\text { notas explicativas. }\end{array}$ \\
\hline Possível & $\begin{array}{l}\text { Pode requerer, mas, provavelmente, } \\
\text { não irá requerer uma saída de } \\
\text { recursos. }\end{array}$ & $\begin{array}{l}\text { Não será reconhecida nenhuma provisão, mas o } \\
\text { passivo contingente deve ser divulgado em notas } \\
\text { explicativas. }\end{array}$ \\
\hline Remota & $\begin{array}{l}\text { Remota probabilidade de uma saída } \\
\text { de recursos. }\end{array}$ & $\begin{array}{l}\text { Não será reconhecida nenhuma provisão, nem } \\
\text { deve ser divulgado em notas explicativas. }\end{array}$ \\
\hline
\end{tabular}

Fonte: adaptado do CPC 25 (COMITÊ DE PRONUNCIAMENTOS CONTÁBEIS, 2009).

Percebe-se, por meio das informações contidas no Quadro 1, que, quando a contingência é considerada provável, há o reconhecimento da provisão e o item aparece no Balanço Patrimonial complementado por nota explicativa. No entanto, quando é considerada possível, não deve ser feito o registro contábil, embora deva ser divulgada em notas explicativas. Quando a possibilidade é remota, não ocorre nem o registro nem a divulgação em notas explicativas.

Já as estimativas devem levar em consideração os riscos e as incertezas que, inevitavelmente, estão ligados aos eventos ocorridos. O risco descreve a variabilidade de desfechos possíveis, e a incerteza não deve justificar a escolha do desfecho mais adverso. O desfecho a ser considerado deve ser o mais provável. As provisões devem ser reavaliadas e ajustadas a cada data de balanço para refletir a melhor estimativa corrente. A provisão deve ser revertida caso deixe de ser provável a saída de recursos para a liquidação da obrigação (COMITÊ DE PRONUNCIAMENTOS CONTÁBEIS, 2009). cam tornar algo evidente e público, no que se refere às informações contábeis.

A divulgação de informações contábeis tem o objetivo de auxiliar os usuários na tomada de decisão. Para isso, as informações precisam ser relevantes e completas. Segundo Hendriksen e Van Breda (1999), para se conseguir uma divulgação apropriada, é necessário responder a três perguntas fundamentais: para quem divulgar? Qual a finalidade da informação divulgada? Quanto divulgar?

As demonstrações contábeis têm a finalidade de fornecer informações úteis à tomada de decisão que devem ser divulgadas, principalmente, a seus usuários primários: acionistas, outros investidores e credores. As decisões tomadas por esses grupos são bem definidas e simples: os investidores decidem, basicamente, sobre compra, manutenção ou venda, e os credores sobre conceder crédito ou não. Porém, existem os destinatários secundários, dos quais não se conhecem as decisões: funcionários, clientes, governo e público em geral (COMITÊ DE PRONUNCIAMENTOS CONTÁBEIS, 
2011; HENDRIKSEN; VAN BREDA, 1999).

A Orientação Técnica OCPC 07 (COMITÊ DE PRONUNCIAMENTOS CONTÁBEIS, 2014) esclarece e reforça que, nas demonstrações contábeis e respectivas notas explicativas, sejam divulgadas informações relevantes que, de fato, façam a diferença nas decisões que possam ser tomadas pelos usuários. A contabilidade deve expressar, de forma apropriada, a situação patrimonial e financeira da entidade e as mutações ocorridas no período por meio da divulgação das demonstrações contábeis exigidas pelo artigo 176 da Lei 6.404/1976 (BRASIL, 1976). São obrigatórias as seguintes demonstrações: balanço patrimonial, demonstração dos lucros ou prejuízos acumulados, demonstração do resultado do exercício, demonstração dos fluxos de caixa e demonstração do valor adicionado. O CPC 26 R1 (COMITÊ DE PRONUNCIAMENTOS CONTÁBEIS, 2011) acrescenta a divulgação da demonstração do resultado abrangente e a demonstração das mutações do patrimônio líquido, que inclui a demonstração dos lucros ou os prejuízos acumulados.

O disclosure pode ser apresentado de forma obrigatória ou voluntária. A divulgação obrigatória corresponde à abrangência das informações exigidas por lei, envolvendo os requerimentos de informações para registro das companhias abertas e as demais informações periódicas exigidas pelas comissões de valores mobiliários, como a publicação das demonstrações contábeis. Quanto à divulgação voluntária, ela se refere à veiculação de toda informação que seja útil para a tomada de decisões pelos diversos usuários, envolve informações que não são exigidas por lei, mas que oferecem maior transparência (LIMA, 2007; OLIVEIRA; BENETTI; VARELA, 2011).
Por meio do quadro 2, pode-se perceber que a divulgação baseada em Associação verifica a existência de associação entre o disclosure e as variáveis de mercado, por exemplo, o preço das ações da empresa. Já a Divulgação baseada em Eficiência engloba a divulgação de informações preferíveis quando não se conhece a informação anterior. Na Divulgação baseada em Julgamento, o gestor exerce sua discricionariedade, decidindo divulgar ou não determinadas informações. Desse modo, este estudo se enquadra, de forma adaptada, como Divulgação Baseada em Associação, pois trata de analisar a divulgação da informação, mas sem relacionar com os efeitos causados nos agentes.

As informações sobre o passivo contingente devem ser divulgadas em notas explicativas, que, além de fornecer informações adicionais sobre as demonstrações contábeis, oferecem descrições narrativas ou segregações, abertura de itens divulgados nessas demonstrações e informação acerca de itens que não se enquadram nos critérios de reconhecimento nas demonstrações contábeis (COMITÊ DE PRONUNCIAMENTOS CONTÁBEIS, 2011). A divulgação das informações sobre as contingências de uma organização contribui para melhor avaliação da entidade no mercado.

A Divulgação do Passivo Contingente é importante para o mercado de capitais, no qual as empresas estão inseridas, pois essa evidenciação demonstra a forma como as empresas lidam com os riscos potenciais ligados à sua atividade. Essas informações, se adequadamente divulgadas, impactam os modelos de avaliação das empresas, reduzindo as incertezas, diminuindo a assimetria de informações, interferindo no valor de mercado da empresa e podendo dar aos usuários condições de escolher entre

Quadro 2 - Tipos de Disclosure

Tipos de Disclosure

Baseada em Associação Examinam-se a relação e os efeitos nos agentes durante o evento do disclosure.

Baseada em Eficiência

Baseada em Julgamento Analisa-se a existência de arranjos eficientes no disclosure que seriam preferidos incondicionalmente.

Examina-se a discricionariedade que os gestores exercem com relação às decisões do disclosure.

Fonte: elaborado a partir de Verrecchia (2001 apud MURCIA; SANTOS, 2009). 
estabelecer ou manter relações com a organização (PRADO, 2014).

Conforme mencionado, as provisões e os passivos contingentes devem ser divulgados nas demonstrações contábeis e em notas explicativas (HENDRIKSEN; VAN BREDA, 1999). A divulgação do passivo contingente está prevista no artigo 176 da Lei 6.404/1976, no parágrafo referente às notas explicativas, assim, descrito: "§ 50 As notas explicativas devem: [...] IV - indicar [...] d) os ônus reais constituídos sobre elementos do ativo, as garantias prestadas a terceiros e outras responsabilidades eventuais ou contingentes; [...]." (BRASIL, 1976, on-line).

Assim, conforme as exigências dos itens 84 a 92 do CPC 25 (COMITÊ DE PRONUNCIAMENTOS CONTÁBEIS, 2009), para cada classe de provisão, a entidade deve divulgar o valor contábil no início e no fim do período; as provisões adicionais feitas no período, incluindo aumentos nas provisões existentes; os valores utilizados (ou seja, incorridos e baixados contra a provisão) durante o período; os valores não utilizados revertidos durante o período; e o aumento durante o período no valor descontado ao valor presente, proveniente da passagem do tempo, e o efeito de qualquer mudança na taxa de desconto. Não é exigida informação comparativa.

A entidade deve divulgar, em notas explicativas para cada classe de passivo contingente, na data do balanço, uma breve descrição da natureza do passivo contingente (trabalhista, tributária, cível e ambiental) e, quando praticável, a estimativa do seu efeito financeiro, conforme as regras de mensuração, considerando a melhor estimativa, os riscos e as incertezas; a indicação das incertezas relacionadas ao valor ou ao momento de ocorrência de qualquer saída e a possibilidade de qualquer reembolso (COMITÊ DE PRONUNCIAMENTOS CONTÁBEIS, 2009).

O CPC 25 (COMITÊ DE PRONUNCIAMENTOS CONTÁBEIS, 2009) estabelece ainda que, quando a provisão e o passivo contingente surgirem do mesmo conjunto de circunstâncias, a entidade deve fazer a divulgação exigida de forma que evidencie a ligação entre a provisão e o passivo contingente. E, caso alguma das informações exigidas não forem divulgadas por não ser praticável, a entidade deve divulgar esse fato.

O Sistema de Governança Corporativa traz alguns princípios básicos: transparência, que consiste na divulgação de informações de interesse dos envolvidos e não apenas os exigidos nas leis e nos regulamentos; equidade, tratamento justo de todos os sócios e demais partes interessadas; prestação de contas, os agentes de governança devem prestar contas de modo claro, compreensivo, preciso e tempestivo, assumindo a consequência de seus atos e agindo com responsabilidade; e responsabilidade corporativa, que é o zelo pela viabilidade econômico-financeira da organização, minimizando os impactos negativos e aumentando os positivos inerentes às suas operações (IBGC, 2017).

A BM\&FBovespa criou os segmentos especiais de listagem das ações após perceber que era necessário ter segmentos adequados aos diferentes perfis de empresas, para que o mercado de capitas se desenvolva. Os segmentos especiais são: Bovespa Mais, Bovespa Mais Nível 2, Novo Mercado, Nível 2 e Nível 1. Além desses segmentos, a BM\&FBovespa possui, ainda, o Segmento Básico, que não conta com regras diferenciadas de governança corporativa (BM\&FBOVESPA, 2017).

O Novo Mercado estabeleceu um padrão altamente diferenciado de governança corporativa. Tornou-se o padrão exigido pelos investidores para novas aberturas de capital, recomendado para empresas que pretendem fazer ofertas grandes e direcionadas a qualquer tipo de investidores. A listagem nesse segmento acarreta a adoção de um conjunto de regras societárias que ampliam os direitos dos acionistas, além da adoção de uma política de divulgação de informações mais transparente e abrangente (BM\&FBOVESPA, 2017).

O Nível 2 é semelhante ao Novo Mercado, com algumas exceções. Por exemplo, ele permite a existência de ações ordinárias e preferenciais com direito a voto em situações críticas. No Novo Mercado, somente são permiti- 
das ações ordinárias. Para ser classificada nesse nível, a empresa precisa atender às exigências do Nível 1, além disso, adotar outras práticas de governança (BM\&FBOVESPA, 2017).

As companhias listadas no Nível 1 devem adotar práticas que favoreçam a transparência e o acesso às informações, divulgando informações adicionais às exigidas em lei. A classificação nesse nível permite a existência de ações ordinárias e preferências, conforme a legislação societária, a manutenção de uma parcela mínima de ações em circulação, a melhoria nas informações trimestrais e a divulgação de informações sobre partes relacionadas (BM\&FBOVESPA, 2017).

\section{METODOLOGIA}

Em relação à natureza, este estudo pode ser considerado qualitativo, por utilizar a análise de conteúdo ao coletar os dados nas notas explicativas. Michel (2015, p. 40) destaca que "a pesquisa qualitativa se propõe a colher e a analisar dados descritivos obtidos diretamente da situação estudada; enfatiza o processo mais que o resultado, para o que precisa e retrata a perspectiva dos participantes."

Quanto aos objetivos, esta pesquisa pode ser classificada como descritiva, uma vez que visa identificar, relatar e comparar o nível de divulgação do passivo contingente dos bancos listados nos segmentos diferenciados de governança corporativa da BM\&FBovespa nos demonstrativos financeiros de 2014 a 2016.

Quanto aos procedimentos, esta pesquisa é documental, pois se baseia em materiais que ainda não receberam um tratamento analítico ou que podem ser reelaborados de acordo com os objetivos da pesquisa; por exemplo, as demonstrações financeiras e as notas explicativas observadas neste estudo. Isto é, esse tipo de investigação visa selecionar, tratar e interpretar a informação bruta, buscando extrair algum sentido (ALMEIDA, 2014; BEUREN, 2006).

Este estudo tem como universo a ser investigado os bancos listados na BM\&FBovespa, classificados nos segmentos diferenciados de Governança Corporativa em 2 de dezembro de 2016. Dessa maneira, a população desta pesquisa é composta por 10 empresas listadas no Setor Financeiro, subsetor Intermediários Financeiros, Bancos, conforme Quadro 3:

Quadro 3 - População da Pesquisa

\begin{tabular}{|c|c|c|}
\hline Razão Social & Código & Governança Corporativa \\
\hline Banco ABC Brasil S.A. & ABC BRASIL & Nível 2 \\
\hline Banco Bradesco S.A. & BRADESCO & Nível 1 \\
\hline Banco Brasil S.A. & BRASIL & Novo Mercado \\
\hline Banco Estado do Rio Grande do & BANRISUL & Nível 1 \\
\hline Sul S.A. & INDUSVAL & Nível 2 \\
\hline Banco Indusval S.A. & BANCO PAN & Nível 1 \\
\hline Banco Pan S.A. & PINE & Nível 2 \\
\hline Banco Pine S.A. & ITAUSA & Nível 1 \\
\hline Itausa Investimentos Itaú S.A. & ITAUUNIBANCO & Nível 1 \\
\hline Itaú Unibanco Holding S.A. & PARANA & Nível 1 \\
\hline Paraná Banco S.A. & & \\
\hline
\end{tabular}

Fonte: dados da pesquisa (2017). 
Para a análise de dados, utilizou-se a técnica de análise de conteúdo. Segundo Michel (2015), esta é uma técnica de levantamento de dados que utiliza informações já coletadas. Desenvolveu-se o instrumento para verificação das informações divulgadas pelas entidades. Destarte, o checklist possui 13 itens, sendo nove referentes à divulgação de provisões e quatro itens referentes à divulgação do passivo contingente, conforme quadro 4:

Quadro 4 - Checklist de Divulgação de Provisões e Passivos Contingentes

\begin{tabular}{|c|c|c|c|}
\hline Classe & $\begin{array}{l}\text { Item } \\
\text { CPC }\end{array}$ & Itens & Descrição \\
\hline \multirow{9}{*}{ Provisões } & 84 (a) & 1 & Valor contábil no início e no fim do período \\
\hline & 84 (b) & 2 & $\begin{array}{l}\text { Provisões adicionais feitas no período, incluindo aumentos nas } \\
\text { provisões existentes. }\end{array}$ \\
\hline & $84(c)$ & 3 & $\begin{array}{l}\text { Valores utilizados (ou seja, incorridos e baixados contra a provisão) } \\
\text { durante o período. }\end{array}$ \\
\hline & $84(d)$ & 4 & Valores não utilizados revertidos durante o período. \\
\hline & $84(\mathrm{e})$ & 5 & Aumento durante o período no valor descontado a valor presente. \\
\hline & 85 (a) & 6 & Breve descrição da natureza da obrigação. \\
\hline & 85 (a) & 7 & Cronograma esperado de saídas. \\
\hline & 85 (b) & 8 & Indicação das incertezas sobre o valor ou o cronograma das saídas. \\
\hline & 85 (c) & 9 & Valor de qualquer reembolso esperado. \\
\hline \multirow{4}{*}{$\begin{array}{l}\text { Passivos } \\
\text { Contingentes }\end{array}$} & 86 & 10 & Breve descrição da natureza do passivo contingente. \\
\hline & 86 (a) & 11 & Estimativa de seu efeito financeiro. \\
\hline & 86 (b) & 12 & $\begin{array}{l}\text { Indicação das incertezas relacionadas ao valor ou ao momento de } \\
\text { ocorrência de saídas. }\end{array}$ \\
\hline & $86(c)$ & 13 & Possibilidade de qualquer reembolso. \\
\hline
\end{tabular}

Fonte: elaborado a partir do CPC 25 Comitê de Pronunciamentos Contábeis (2009), Silva (2012), Castro Júnior (2013) e Garcia (2015).

Para identificar o nível de divulgação, adotou-se a estratégia de escores, no qual se atribuiu o valor 1 (um) para a empresa que divulga o item apontado no checklist e 0 (zero) para aquela que não divulga. Assim, para identificar o nível de divulgação do passivo contingente, optou-se por levantar a soma dos itens de divulgação e dividi-lo pelo número total de itens definidos no checklist (13). Desse modo, a soma dos escores pode chegar a 13, correspondendo, portanto, ao nível de divulgação de $100 \%$. No Quadro 5, estão elencadas características, medidas adotadas e fonte de dados utilizadas.

Quadro 5 - Características, medidas adotadas e fonte de dados

Característica

\begin{tabular}{|c|c|}
\hline Tamanho & Valor do Ativo total \\
\hline Idade & $\begin{array}{c}\text { Diferença entre o ano base e } \\
\text { o ano de constituição }\end{array}$ \\
\hline $\begin{array}{c}\text { Nível de Governança } \\
\text { Corporativa }\end{array}$ & $\begin{array}{c}\text { Novo Mercado, Nível 1 e } \\
\text { Nível 2 }\end{array}$ \\
\hline Auditoria & Firma de Auditoria \\
\hline
\end{tabular}

Fonte: elaborado pelos autores deste trabalho (2017).

\section{Fonte de dados}

Balanço Patrimonial em 31/12/2016

Formulário de Referência 2016 - item - Dados cadastrais - Dados gerais

Boletim Diário de informações em 2/12/2016 disponível no website BM\&FBovespa

Relatório de Auditoria 31/12/2016 
Conforme quadro 5, o tamanho da empresa é definido pelo valor do Ativo Total, em milhares de reais, em 31/12/2016; e a idade da empresa é dada pela diferença entre o ano-base (2016) e o ano de sua constituição. Em relação ao nível de governança corporativa, adotou-se a classificação apresentada no Boletim Diário de Informações (BDI) da BM\&FBovespa de $02 / 12 / 2016$. A característica auditoria será verificada no Relatório de Auditoria divulgado pela companhia em 31 de dezembro de 2016 por meio de identificação da firma de auditoria que realiza o serviço na empresa.

Foram examinados os tipos e a frequência de divulgação dos passivos contingentes evidenciados, considerando-se, para tal verificação, o item 10 do checklist. Desse modo, por meio da técnica de análise de conteúdo, foram analisadas nas notas explicativas dos exercícios encerrados em 31 de dezembro de 2014, 2015 e 2016, a natureza de passivos contingentes, podendo ser classificados como trabalhistas, tributários, cíveis e ambientais (FARIAS, 2004), além da frequência de ocorrência para cada tipo.

\section{DISCUSSÃO E RESULTADOS}

\subsection{ANÁLISE POR EMPRESA}

A análise dos dados balizou-se no estudo por empresas. Foram pesquisadas em ordem: ABC Brasil, Bradesco, Brasil, Banrisul, Indusval, Banco Pan, Pine, Itausa, Itauunibanco e Paraná. Para fins deste artigo, apresenta-se: BANRISUL; ITAUUNIBANCO; BRASIL (níveis maiores de divulgação); ABC BRASIL; BANCO PAN; BRADESCO (níveis menores de divulgação).

Entre as empresas com os maiores níveis de divulgação, está o BANRISUL, que apresenta o terceiro maior nível de divulgação de $69 \%$. A entidade possui o quarto maior ativo, com o valor de R $\$ 70,15$ bilhões. Foi fundada, em 1928, e, até 2016, estava com 88 anos. Está listada no Nível 1 de governança corporativa. Em 2014 e 2015, suas demonstrações financeiras foram auditadas pela firma de auditoria Ernst \& Young; porém, em 2016, foi audita pela KPMG Auditores Independentes. A KPMG destacou, em seu parecer, o assunto sobre Provisões e Passivos Contingentes devido à relevância dos valores e julgamentos envolvidos na avaliação e na mensuração das provisões e passivos contingentes. Ao concluir a auditoria, consideraram adequado o nível de provisionamento e divulgação das demonstrações contábeis consolidadas.

A organização apresenta três tipos de passivos contingentes durante o período com a mesma frequência de evidenciação: cível, tributário e trabalhista. As contingências fiscais decorrem, principalmente, de impostos municipais e federais. Os processos trabalhistas referem-se, principalmente, a pedidos de horas extras, reintegração e equiparação salarial. As ações cíveis referem-se, principalmente, a ações de danos morais, repetição do indébito, cadernetas de poupança e financiamento imobiliário. Durante o período analisado, a companhia manteve o nível de divulgação em $69 \%$. A empresa não divulgou informações sobre o aumento durante o período no valor descontado a valor presente, o cronograma esperado de saídas dos recursos e o valor ou possibilidade de qualquer reembolso esperado.

Quadro 6 - Nível de divulgação Banrisul

\begin{tabular}{|c|c|c|c|c|c|c|c|c|c|c|c|c|c|c|}
\hline Item/Ano & $\mathbf{1}$ & $\mathbf{2}$ & $\mathbf{3}$ & $\mathbf{4}$ & $\mathbf{5}$ & $\mathbf{6}$ & $\mathbf{7}$ & $\mathbf{8}$ & $\mathbf{9}$ & $\mathbf{1 0}$ & $\mathbf{1 1}$ & $\mathbf{1 2}$ & $\mathbf{1 3}$ & Nível \\
\hline $\mathbf{2 0 1 4}$ & 1 & 1 & 1 & 1 & 0 & 1 & 0 & 1 & 0 & 1 & 1 & 1 & 0 & $69 \%$ \\
\hline $\mathbf{2 0 1 5}$ & 1 & 1 & 1 & 1 & 0 & 1 & 0 & 1 & 0 & 1 & 1 & 1 & 0 & $69 \%$ \\
\hline $\mathbf{2 0 1 6}$ & 1 & 1 & 1 & 1 & 0 & 1 & 0 & 1 & 0 & 1 & 1 & 1 & 0 & $69 \%$ \\
\hline
\end{tabular}

Fonte: dados da pesquisa (2017). 
O Itauunibanco e o Brasil apresentaram o mesmo nível de divulgação de $77 \%$. O Itauunibanco possui o segundo maior ativo total com o valor de R\$ 1,35 trilhão. Até 2016, estava com 73 anos de idade. Está classificada no Nível 1 de governança corporativa, e suas demonstrações financeiras são auditadas pela PricewaterhouseCoopers ( $\mathrm{PwC})$. Os auditores independentes consideraram que os critérios e as premissas adotados pela Administração para a determinação da provisão para passivos contingentes, bem como as divulgações efetuadas, foram apropriados.

A companhia apresentou os três tipos de passivos contingentes durante o período: tributário, trabalhista e cível. As ações cíveis referem-se a ações indenizatórias por danos morais e materiais ou de cobranças. Os processos tributários são relativos a INSS, imposto de ren- da, contribuição social, imposto sobre serviços, PIS e COFINS. As contingências trabalhistas têm relação com processos em que se discutem pretensos direitos trabalhistas, relativos à legislação trabalhista específica da categoria profissional, como horas extras, equiparação salarial, reintegração, adicional de transferência, complemento de aposentadoria e outros.

Não houve a divulgação sobre o aumento durante o período no valor descontado a valor presente, cronograma esperado de saídas e possibilidade de qualquer reembolso. O banco reconhece Ativos Dados em Garantia de Contingências, que são relativos a processos de passivos contingentes e estão vinculados a Títulos e Valores Mobiliários, basicamente Letras Financeiras do Tesouro ou depósitos em dinheiro.

Quadro 7 - Nível de divulgação Itauunibanco

\begin{tabular}{|c|c|c|c|c|c|c|c|c|c|c|c|c|c|c|}
\hline Item/Ano & 1 & 2 & 3 & 4 & 5 & $\mathbf{6}$ & $\mathbf{7}$ & $\mathbf{8}$ & $\mathbf{9}$ & $\mathbf{1 0}$ & $\mathbf{1 1}$ & $\mathbf{1 2}$ & $\mathbf{1 3}$ & Nível \\
\hline $\mathbf{2 0 1 4}$ & 1 & 1 & 1 & 1 & 0 & 1 & 0 & 1 & 1 & 1 & 1 & 1 & 0 & $\mathbf{7 7 \%}$ \\
\hline $\mathbf{2 0 1 5}$ & 1 & 1 & 1 & 1 & 0 & 1 & 0 & 1 & 1 & 1 & 1 & 1 & 0 & $\mathbf{7 7 \%}$ \\
\hline $\mathbf{2 0 1 6}$ & 1 & 1 & 1 & 1 & 0 & 1 & 0 & 1 & 1 & 1 & 1 & 1 & 0 & $\mathbf{7 7 \%}$ \\
\hline
\end{tabular}

Fonte: dados da pesquisa (2017).

O BRASIL possui o maior ativo total, entre as empresas da amostra, com o valor de $\mathrm{R} \$ 1,38$ trilhão. É a única desta pesquisa listada no Novo Mercado e também a mais antiga, fundada em 1808; e, em 2016, completou 208 anos. Suas demonstrações financeiras são auditadas pela firma KPMG Auditores Independentes. A auditoria considerou adequado o nível de provisionamento e a divulgação das provisões e passivos contingente.

A organização apresenta três tipos de passivos contingentes durante o período com a mesma frequência de evidenciação: cível, tributário e trabalhista. Os processos trabalhistas são movidos, em grande maioria, por ex-empregados ou sindicatos da categoria com reclamações sobre indenizações, horas extras, descaracterização de jornada de trabalho, adicional de função e representação e outros. A maioria das ações tributárias estão relacionadas com imposto sobre serviços, imposto de renda, contribuição social, PIS, COFINS e contribuições previdenciárias. Entre as ações cíveis, destacam-se as de cobrança de diferença de correção monetária de cadernetas de poupança e depósitos judiciais relativos ao período dos Planos Econômicos (Plano Bresser, Plano Verão e Planos Collor I e II).

Durante o período analisado, a empresa apresentou um nível de divulgação de $77 \%$. Foi a única que pontuou no item 7 do checklist, divulgando o cronograma esperado de saída dos benefícios. A companhia não apresentou informações relacionadas ao ajuste a valor presente dos valores registrados e a possibilidade ou valor de qual- 
quer reembolso esperado. O banco efetua depósitos judiciais em garantia no Banco ou em outra instituição financeira oficial, como meio de pagamento ou como meio de garantir o pagamento de condenações, indenizações, acordos e demais despesas decorrentes de processos judiciais.

Quadro 8 - Nível de divulgação Brasil

\begin{tabular}{|c|c|c|c|c|c|c|c|c|c|c|c|c|c|c|}
\hline Item/Ano & $\mathbf{1}$ & $\mathbf{2}$ & $\mathbf{3}$ & $\mathbf{4}$ & $\mathbf{5}$ & $\mathbf{6}$ & $\mathbf{7}$ & $\mathbf{8}$ & $\mathbf{9}$ & $\mathbf{1 0}$ & $\mathbf{1 1}$ & $\mathbf{1 2}$ & $\mathbf{1 3}$ & Nível \\
\hline $\mathbf{2 0 1 4}$ & 1 & 1 & 1 & 1 & 0 & 1 & 1 & 1 & 0 & 1 & 1 & 1 & 0 & $\mathbf{7 7 \%}$ \\
\hline $\mathbf{2 0 1 5}$ & 1 & 1 & 1 & 1 & 0 & 1 & 1 & 1 & 0 & 1 & 1 & 1 & 0 & $\mathbf{7 7 \%}$ \\
\hline $\mathbf{2 0 1 6}$ & 1 & 1 & 1 & 1 & 0 & 1 & 1 & 1 & 0 & 1 & 1 & 1 & 0 & $\mathbf{7 7 \%}$ \\
\hline
\end{tabular}

Fonte: dados da pesquisa (2017).

Entre os bancos contidos na amostra deste estudo, que possuem os menores níveis de divulgação, está o $\mathrm{ABC}$ Brasil, que apresenta o terceiro pior nível de divulgação. A entidade possui o quarto menor ativo total, com o valor de R \$25,4 bilhões. É uma empresa considerada jovem, com 33 anos de idade, fundada em 1983. Está listada no segmento Nível 2 de governança corporativa, e suas demonstrações são auditadas por uma das firmas de auditoria classificadas como Big Four, a Ernst \& Young.

Constatou-se, por meio da análise das notas explicativas da empresa em estudo, que os tipos de passivos contingentes de maior frequência de divulgação são cíveis e tributários, uma vez que as contingências trabalhistas só foram consideradas como perda possível em 2016. Os processos fiscais são referentes a imposto de renda, contribuição social, imposto sobre serviços, encargos previdenciários e compensações não homologadas de tributos. As ações cíveis referem-se a pedidos de anulação de débitos referentes a operações de crédito e solicitação de pagamento de diferença no preço de venda de títulos oferecidos para pagamento de empréstimos.

Em 2014 e 2015, o nível de divulgação foi 46\%. Em 2016, o nível de divulgação reduziu para 38\%. Isso ocorreu porque a companhia realizou a divulgação em conjunto dos valores referentes à constituição e à reversão, não sendo possível identificar os valores relativos a cada item separadamente.

Quadro 9 - Nível de divulgação ABC Brasil

\begin{tabular}{|c|c|c|c|c|c|c|c|c|c|c|c|c|c|c|}
\hline Item/Ano & $\mathbf{1}$ & $\mathbf{2}$ & $\mathbf{3}$ & $\mathbf{4}$ & $\mathbf{5}$ & $\mathbf{6}$ & $\mathbf{7}$ & $\mathbf{8}$ & $\mathbf{9}$ & $\mathbf{1 0}$ & $\mathbf{1 1}$ & $\mathbf{1 2}$ & $\mathbf{1 3}$ & Nível \\
\hline $\mathbf{2 0 1 4}$ & 1 & 1 & 1 & 0 & 0 & 1 & 0 & 0 & 0 & 1 & 1 & 0 & 0 & $\mathbf{4 6 \%}$ \\
\hline $\mathbf{2 0 1 5}$ & 1 & 1 & 1 & 0 & 0 & 1 & 0 & 0 & 0 & 1 & 1 & 0 & 0 & $\mathbf{4 6 \%}$ \\
\hline $\mathbf{2 0 1 6}$ & 1 & 0 & 1 & 0 & 0 & 1 & 0 & 0 & 0 & 1 & 1 & 0 & 0 & $\mathbf{3 8 \%}$ \\
\hline
\end{tabular}

Fonte: dados da pesquisa (2017).

O BANCO PAN é a companhia que apresenta o segundo pior nível de divulgação. A organização possui o quinto menor ativo total entre as empresas analisadas, com o valor de $\mathrm{R} \$ 27,77$ bilhões. A empresa foi fundada em 1966 e, em 2016, estava com 50 anos. Está classificada no Nível 1 de governança corporativa. Suas demonstrações financeiras são auditadas pela firma de auditoria PricewaterhouseCoopers (PwC). Os passivos contingentes classificados como perda possível, divulgados pela empresa, são apenas do tipo tributário. Eles são referentes a processos sobre imposto de renda, contribuição social, imposto de renda retido na fonte e imposto sobre serviços.

Durante o período analisado, a companhia apresentou o mesmo nível de divulgação, 38\%. A empresa divulgou, em conjunto, os valores referentes à constituição e à reversão, não sendo 
possível identificar os valores relativos a cada item separadamente. Nesse caso, foi atribuído 0 (zero) aos itens 2 e 4 do checklist.

Quadro 10 - Nível de divulgação Banco Pan

\begin{tabular}{|c|c|c|c|c|c|c|c|c|c|c|c|c|c|c|}
\hline Item/Ano & $\mathbf{1}$ & $\mathbf{2}$ & $\mathbf{3}$ & $\mathbf{4}$ & $\mathbf{5}$ & $\mathbf{6}$ & $\mathbf{7}$ & $\mathbf{8}$ & $\mathbf{9}$ & $\mathbf{1 0}$ & $\mathbf{1 1}$ & $\mathbf{1 2}$ & $\mathbf{1 3}$ & Nível \\
\hline $\mathbf{2 0 1 4}$ & 1 & 0 & 1 & 0 & 0 & 1 & 0 & 0 & 0 & 1 & 1 & 0 & 0 & $\mathbf{3 8 \%}$ \\
\hline $\mathbf{2 0 1 5}$ & 1 & 0 & 1 & 0 & 0 & 1 & 0 & 0 & 0 & 1 & 1 & 0 & 0 & $\mathbf{3 8 \%}$ \\
\hline $\mathbf{2 0 1 6}$ & 1 & 0 & 1 & 0 & 0 & 1 & 0 & 0 & 0 & 1 & 1 & 0 & 0 & $\mathbf{3 8 \%}$ \\
\hline
\end{tabular}

Fonte: dados da pesquisa (2017).

O BRADESCO apresenta o pior nível de divulgação entre as empresas analisadas. A companhia possui o terceiro maior ativo total, com o valor de R\$ 1,19 trilhão. Foi fundada em 1943 e, até 2016, estava com 73 anos de idade. Está listada no Nível 1 de governança corporativa da BM\&FBovespa, e suas demonstrações financeiras são auditadas pela KPMG Auditores Independentes. No Relatório de Auditoria de 2016 da companhia, os auditores destacaram as provisões e os passivos contingentes como um dos principais assuntos de auditoria devido à relevância, à complexidade e ao julgamento envolvido na avaliação, mensuração, definição do momento para o reconhecimento e a divulgação. Os auditores consideram adequados os níveis de provisionamento e de divulgação apresentados pela empresa.

A organização é parte em processos judiciais de natureza trabalhista, cível e fiscal, decorrentes do curso normal de suas atividades. O tipo de passivo contingente com maior frequência de divulgação é o tributário. Não foram descritos processos trabalhistas ou cíveis, como passivos contingentes. Os principais processos tributários com risco de perda possível estão relacionados com imposto de renda, contribuição social, imposto sobre serviços, PIS e COFINS.

Durante o período analisado, o nível de evidenciação das contingências se manteve em 31\%, o mais baixo nível entre as empresas analisadas. Esse nível deve-se, entre outros aspectos, ao fato de a companhia realizar a divulgação em conjunto dos valores referentes à constituição, à reversão e às baixas, não sendo possível identificar os valores relativos a cada item separadamente. Nesse caso, foi atribuído 0 (zero) aos itens 2, 3 e 4 do checklist.

Quadro 11 - Nível de divulgação Bradesco

\begin{tabular}{|c|c|c|c|c|c|c|c|c|c|c|c|c|c|c|}
\hline Item/Ano & $\mathbf{1}$ & $\mathbf{2}$ & $\mathbf{3}$ & $\mathbf{4}$ & $\mathbf{5}$ & $\mathbf{6}$ & $\mathbf{7}$ & $\mathbf{8}$ & $\mathbf{9}$ & $\mathbf{1 0}$ & $\mathbf{1 1}$ & $\mathbf{1 2}$ & $\mathbf{1 3}$ & Nível \\
\hline $\mathbf{2 0 1 4}$ & 1 & 0 & 0 & 0 & 0 & 1 & 0 & 0 & 0 & 1 & 1 & 0 & 0 & $\mathbf{3 1 \%}$ \\
\hline $\mathbf{2 0 1 5}$ & 1 & 0 & 0 & 0 & 0 & 1 & 0 & 0 & 0 & 1 & 1 & 0 & 0 & $\mathbf{3 1 \%}$ \\
\hline $\mathbf{2 0 1 6}$ & 1 & 0 & 0 & 0 & 0 & 1 & 0 & 0 & 0 & 1 & 1 & 0 & 0 & $\mathbf{3 1 \%}$ \\
\hline
\end{tabular}

Fonte: dados da pesquisa (2017).

Foi verificada a existência de diferenças no nível de divulgação entre os segmentos de Governança Corporativa Novo Mercado, Nível 2 e Nível 1. Durante o período, o segmento Nível 1 manteve o nível de 59\%, e o Novo Mercado permaneceu com o nível de 77\%. Porém, o Nível 2 apresentou os níveis de 54\%, 54\% e 51\% nos anos de 2014, 2015 e 2016, respectivamente. Após a comparação entre as médias globais dos segmentos, observou-se que existe uma diferença relevante entre o Novo Mercado (77\%) e o Nível 1 (59\%) e Nível 2 (53\%). 


\section{CONCLUSÃO}

As exigências relacionadas à evidenciação de contingências, provisões e passivos contingentes não são recentes. Pode-se citar, por exemplo, que a Lei 6.404/1976 já previa a divulgação das contingências. Contudo, a orientação quanto à forma de divulgação e ao conteúdo a ser divulgado está prevista no CPC 25 (COMITÊ DE PRONUNCIAMENTOS CONTÁBEIS, 2009).

Foram levantadas algumas características dos bancos para diferenciar melhor a amostra analisada. As cinco empresas com mais de 50 anos possuem os maiores ativos totais e estão classificadas no Nível 1 ou no Novo Mercado. A maior parte é auditada pelas quatro maiores empresas de auditoria do mundo, conhecidas como Big Four. Brasil, a maior companhia e mais antiga, foi uma das que obteve o melhor nível de evidenciação, seguida da segunda maior companhia, Itauunibanco.

Foram examinados os tipos de passivos contingentes divulgados e a frequência com que eles eram evidenciados. Constatou-se que os passivos contingentes com maiores relevâncias foram os de natureza tributária, trabalhista e cível, respectivamente. Nenhuma das empresas apresentou passivos contingentes ambientais nas demonstrações financeiras, e isso mostra que essas empresas não têm a apresentação do dano causado ao meio ambiente.

Percebeu-se que as empresas não vêm cumprindo as exigências estabelecidas no CPC 25 (COMITÊ DE PRONUNCIAMENTOS CONTÁBEIS, 2009) em sua totalidade, apesar de estarem listadas nos segmentos diferenciados de governança corporativa, que prezam por transparência e abrangência nas informações divulgadas. Ao avaliar o nível de divulgação do passivo contingente dos bancos, concluiu-se que duas empresas apresentaram o melhor nível de disclosure, o Brasil e o Itauunibanco. Ambas obtiveram a mesma média de evidenciação durante o período. Observou-se que o Bradesco apresentou o nível mais baixo de evidenciação durante o período. Houve uma dife- rença relevante, de 46 pontos percentuais, entre o nível mais alto e o mais baixo. A média do nível de divulgação apresentada pelas companhias durante o período analisado foi de $63 \%$. Levando em consideração essa média, seis empresas apresentaram níveis acima da média e quatro empresas ficaram abaixo.

Como limitação da pesquisa, não foi possível afirmar se as empresas omitiram a divulgação de determinados itens ou se eles não eram aplicáveis. Destaque-se, também, o fato de as conclusões deste estudo se limitarem apenas às empresas da amostra. Recomenda-se a realização de estudos abordando outros setores da economia e outros segmentos de governança corporativa.

\section{REFERÊNCIAS}

ALMEIDA, M. de S. Elaboração de projeto, TCC, dissertação e tese: uma abordagem simples, prática e objetiva. 2. ed. São Paulo: Atlas, 2014.

BEUREN, I. M. Como elaborar trabalhos monográficos em contabilidade: teoria e prática. 3. ed. São Paulo: Atlas, 2006.

\section{BM\&FBOVESPA. Evolução dos segmentos} especiais. Disponível em: www.bmfbovespa. com.br/pt br/listagem/acoes/segmentos-de-listagem/sobre-segmentos-de-listagem/evolucao-dos-segmentos-especiais/. Acesso em: 2 nov. 2016

BM\&FBOVESPA. Segmentos de listagem. Disponível em: http://www.bmfbovespa.com. br/ pt_br/listagem/acoes/segmentos-de-listagem/sobre-segmentos-de-listagem/. Acesso em: 15 jan. 2017.

BRASIL. Lei ${ }^{0} \mathbf{6 . 4 0 4}$, de 15 de dezembro de 1976. Dispõe sobre as Sociedades por Ações. Brasília, DF: Presidência da República, 1976. Disponível em: http://www.planalto.gov.br/ccivil_03/LEIS/L6404consol.htm. Acesso em: 15 jan. 2017. 
CAETANO, T. P. et al. Evidenciação do passivo contingencial nas demonstrações contábeis: um estudo nas empresas de papel e celulose. In: CONGRESSO USP DE INICIAÇÃO CIENTÍFICA EM CONTABILIDADE, 7., 2010, São Paulo. Anais [...]. São Paulo: USP, 2010. Disponível em: www.congressousp.fipecafi.org/ web/artigos102010/432.pdf. Acesso em: 16 set. 2016 .

CASTRO JUNIOR, F. F. G. Evidenciação de provisões e passivos contingentes adotados nas empresas brasileiras do setor de energia elétrica listadas na BM\&FBovespa. Fortaleza: Faculdade de Economia, Administração, Atuária e Contabilidade da Universidade Federal do Ceará, 2013. Disponível em: http://www. repositoriobib.ufc.br/000018/00001838.pdf. Acesso em: 16 set 2016.

COMITE DE PRONUNCIAMENTOS CONTÁBEIS (CPC). Pronunciamento Técnico CPC 00 (R1). Estrutura Conceitual para Elaboração e Divulgação de Relatório Contábil - Financeiro. 2011. Disponível em: http://static.cpc.mediagroup.com.br/Documentos/147 CPC00_R1.pdf. Acesso em 18 out 2016.

COMITE DE PRONUNCIAMENTOS CONTÁBEIS. Pronunciamento Técnico CPC 25. Provisões, Passivos Contingentes e Ativos Contingentes. 2009. Disponível em: http://static.cpc.mediagroup.com.br/Documentos/304 CPC_25_rev\%2006.pdf. Acesso em: 16 set. 2016.

COMITÊ DE PRONUNCIAMENTOS CONTÁBEIS. Orientação Técnica OCPC 07. Evidenciação na Divulgação dos Relatórios Contábil-Financeiros de Propósito Geral. 2014. Disponível em: http://static.cpc.mediagroup. com.br/Documentos/488_OCPC_07_Orienta $\% \mathrm{C} 3 \% \mathrm{~A} 7 \% \mathrm{C} 3 \% \mathrm{~A} 3$ o.pdf. Acesso em: 5 fev. 2017.

FARIAS, M. R. S. Divulgação do passivo: um enfoque sobre o passivo contingente no setor químico e petroquímico brasileiro. 2004. 144 f. Dissertação (Mestrado em Controladoria e Contabilidade: Contabilidade) - Faculdade de Economia, Administração e Contabilidade, Universidade de São Paulo, São Paulo, 2004. Disponível em: http://www.teses.usp.br/teses/ disponiveis/12/12136/tde-09012006-121101/ pt-br.php. Acesso em: 16 out. 2016.

FONTELES, I. et al. Determinantes da Evidenciação de Provisões e Contingências por Companhias listadas na BM\&FBovespa. Revista Gestão Organizacional (RGO), Chapecó, v. 6, n. 4, p. 85-98, dez. 2013. Disponível em: http://bell.unochapeco.edu.br/revistas/index. php/rgo/article/view/995/1482. Acesso em: 9 dez. 2016.

GARCIA, Alexandre Schwinden. Divulgação dos passivos contingentes e provisões em empresas do setor industrial: segmento novo mercado da BM\&FBovespa. 2015. $64 \mathrm{f}$. Trabalho de Conclusão de Curso (Graduação) Universidade Federal de Santa Catarina, Santa Catarina, 2015. Disponível em: https://repositorio.ufsc.br/xmlui/handle/123456789/163083. Acesso em: 20 out. 2016.

GELBCKE, E. R. et al. Manual de contabilidade societária: aplicável a todas as sociedades, de acordo com as normas internacionais e do CPC. 2. ed. São Paulo: Atlas, 2013.

HENDRIKSEN, E. S.; VAN BREDA, M. F. Teoria da contabilidade. 5. ed. São Paulo: Atlas, 1999.

IBGC - Instituto Brasileiro de Governança Corporativa. Governança Corporativa. Disponível em: http://www.ibgc.org.br/index.php/governanca/governanca-corporativa. Acesso em: 11 abr. 2017.

LIMA, Gerlando Augusto Sampaio Franco de. Utilização da teoria da divulgação para avaliação da relação do nível de disclosure com o custo da dívida das empresas brasileiras. 
2007. 118 f. Tese (Doutorado em Controladoria e Contabilidade: Contabilidade) - Faculdade de Economia, Administração e Contabilidade, Universidade de São Paulo, São Paulo, 2007. Disponível em: http://www.teses.usp.br/teses/ disponiveis/12/12136/tde-26112007-165145/ pt-br.php. Acesso em: 24 out. 2016.

MICHEL, M. H. Metodologia e pesquisa científica em ciências sociais: um guia prático para acompanhamento da disciplina e elaboração de trabalhos monográficos. 3. ed. São Paulo: Atlas, 2015.

MURCIA, F. D.; SANTOS, A. Fatores determinantes do nível de disclosure voluntário das companhias abertas no Brasil. Revista de Educação e Pesquisa em Contabilidade (REPEC), v. 3, n. 2, p. 72-95, maio 2009. Disponível em: http://www.repec.org.br/index.php/ repec/article/view/68/58. Acesso em: 28 out. 2016.

NIYAMA, J. K.; SILVA, C. A. T. Teoria da Contabilidade. 3. ed. São Paulo: Atlas, 2013.

OLIVEIRA, A. F. de; BENETTI, J. E.; VARELA, P.S. Disclosure das provisões e dos passivos e ativos contingentes: um estudo em empresas listadas na BM\&FBovespa. In: CONGRESSO ANPCONT, 5., 2011, Vitória. Anais [...]. Vitória, 2011. Disponível em: http://congressos.anpcont.org.br/congressos-antigos/v/ images/250-2.pdf. Acesso em: 24 out. 2016.

PRADO, F. J. do. Análise do comportamento da divulgação das informações sobre provisões e passivos contingentes das empresas do setor de energia elétrica listadas na $\mathrm{BM} \&$ FBOVESPA. 2014. Dissertação (Mestrado em Controladoria e Contabilidade) - Faculdade de Economia, Administração e Contabilidade de Ribeirão Preto, Universidade de São Paulo, Ribeirão Preto, 2014. Disponível em: http:// www.teses.usp.br/teses/disponiveis/96/96133/ tde-18082014-102308/pt-br.php. Acesso em: 28 jan. 2017.
SILVA, Thássia Souza da. Análise do cumprimento das exigências de reconhecimento, mensuração e divulgação das provisões e passivos contingentes em empresas de mineração, siderurgia e metalurgia. 2012. 27 f. TCC (Graduação em Ciências Contábeis) - Faculdade de Ciências Econômicas, Universidade Federal do Rio Grande do Sul, Porto Alegre, 2012. Disponível em: http://hdl.handle. net/10183/61944. Acesso em: 16 out. 2016.

SUAVE, Ricardo et al. Divulgação de passivos contingentes nas empresas mais líquidas da BM\&FBovespa. Revista da UNIFEBE, Brusque, SC, v. 1, n. 11, 2013. Disponível em: http://periodicos.unifebe.edu.br/index.php/ revistaeletronicadaunifebe/article/view/130. Acesso em: 16 set. 2016. 